\title{
JOSÉ-ALBERTO MARQUES: O POEMA CONTRA A IMUTABILIDADE ESTÁTICA
}

\author{
Rogério Barbosa da Silva*
}

RESUMO: Leitura de Homeóstatos, de José-Alberto Marques, buscando demonstrar em sua composição o processo dinâmico da escrita poética, a qual atribui ao poema o sentido de um corpo vivo. Ressalta-se que, nesse processo poético, o poeta reinventa a tradição, expondo o poema como um fazer estético-crítico. Para isso, lemos os poucos textos críticos do poeta em contraste com sua poesia e com textos fundamentais para se pensar a poesia experimental, como os de E. M. de Melo e Castro, sobre o poeta e a poesia experimental portuguesa; de Haroldo de Campos, sobre sincronia e diacronia; e de Alberto Pimenta, sobre a poetografia, como elemento de afirmação autônoma do poema perante as tradições líricas.

Palavras-chave: Homeóstatos. José-Alberto Marques. Poesia Experimental Portuguesa.

Sem lentes os olhos perdiam-se na lenta pesquisa da natureza dos nenúfares por enciclopédias e oceanos

(MARQUES, 2011, p. 11)

Conforme nos lembra Melo e Castro, a propósito de Homeóstatos, "homeostasia é constituída pelos mecanismos biológicos de conservação de um ambiente interno constante" (CASTRO, 1995, p. 190). No mesmo texto, Castro ressalta que, nessa série de poemas visuais létricos, o processo de decomposição do verso espacialmente na página e a reorganização dos signos reconstituem o "ambiente interno do organismo vivo que é o poema" (CASTRO, 1995, p. 190).

Ainda que alguns dos poemas dos dez Homeóstatos apresentem ou a reconstituição do verso inicial, ou uma estrutura frásica em verso, não é bem essa reconstituição estrutural do verso que nos permitirá enxergar a permanência do poema. Não é uma questão apenas da desintegração e da reconstituição sintática essa ideia da permanência. O que parece importar ao poeta é a poesia em si. Talvez, por isso, a permanência seja aquilo que nos permite identificar a matéria viva do poema enquanto

\footnotetext{
* Centro Federal de Educação Tecnológica de Minas Gerais, Brasil. E-mail: rogeriobsilvacefet@gmail.com
} 
instância instauradora do poético, isto é, o processo que o instaura, que vive no poema e o transforma também num corpo vivo. Nesse sentido, pode-se tomar estes homeóstatos como uma metafora da poiésis, na medida em que o poema se realiza numa margem, conforme define o próprio Marques, para a qual confluem os conhecimentos, e a partir da qual se ergue o poema. Esse é também o corpo da linguagem, o corpo da literatura, restaurado por uma atitude poetográfica, naquela definição já clássica de Alberto Pimenta, em O Silêncio dos Poetas (A Regra do Jogo, 1978; Cotovia, 2003).

Essas observações indicam no procedimento estético de José-Alberto Marques a utilização da metáfora de Homeóstatos como designação de uma escrita dinâmica cuja sobrevivência depende desse ambiente interno de autoregulação e de autoajustes que a página instaura. Por conseguinte, essa metáfora poderia ser estendida a outras obras do poeta (poética e ficcional), se desvendamos em sua poética as formulações críticas em que ela incide e também seu modo de apreensão das linguagens no processo criativo.

Num dos raros textos sobre seu próprio trabalho em Poemografias (1985), organização de Fernando Aguiar e Silvestre Pestana, o poeta José-Alberto Marques salienta que seu silêncio teórico, numa atitude distinta daquela de seus companheiros da geração experimental, é a sobrevalorização da atividade criativa, uma espécie de "POEPRÁTICA" (MARQUES, 1985, p. 89). Nesse mesmo texto, o poeta destaca: "não me interessa o poema robot do poema, mas o poema, a viagem cósmica, cosmográfica, o olhar de cima e concluir da motricidade tempológica na imutabilidade estática que me rodeia. (MARQUES, 1985, p. 90). Aqui o poeta realiza um deslocamento crítico da espacialidade para a dimensão temporal, e isso é interessante porque, conquanto o espaço seja um elemento importante em seus homeóstatos, ou mesmo em suas "ex-critas", ou nas "aerographias", o poema se inscreve também como uma forma sincrônica da poesia. Evocamos, nesse contexto, a definição de Haroldo de Campos:

A poética sincrônica (estético-criativa), no sentido em que a conceituo para propósitos bem definidos, está imperativamente vinculada às necessidades 
criativas do presente: ela não se guia por uma descrição sincrônica estabelecida no passado, mas quer substituí-la - para efeitos, inclusive, de revisão do panorama diacrônico rotineiro - por uma nova tábua sincrônica que retira sua função da literatura viva do presente. (CAMPOS, 1977, p. 222$3)$.

Se não nos equivocamos, a configuração da página, o suporte do poema, estabelece uma espécie de estaticismo em função do acrisolamento da forma, e isso deriva da atitude conceptual de apreensão e normalização da poesia herdada nas tradições literárias. Assim, libertar o poema instituindo-o como uma homeostase revela-se uma atitude crítica do poema, rompendo com o conceptualismo a priori. Por isso o poeta dirá: "Trata-se de afirmar e assumir que o espaço não existe, ou é apenas a harmonia dos destroços e meteoritos que o tempo solidificado foi injectando e projectando na roda imparável de seu movimento." (MARQUES, 1985, p. 90)

Vejamos o exemplo de um dos seus Homeóstatos (1965), publicado inicialmente no Caderno de Poesia Experimental ${ }^{\circ} 2$ (1966): 
Fig. 1 - Homeóstato 1, José-Alberto Marques, 1965. Imagem de Operação 1 (1967). Também publicado em Poesia Experimental 2 (1966); Antologia da Poesia Concreta em Portugal (1973); Antologia da Poesia Experimental Portuguesa Anos 60 - 80 (2004).

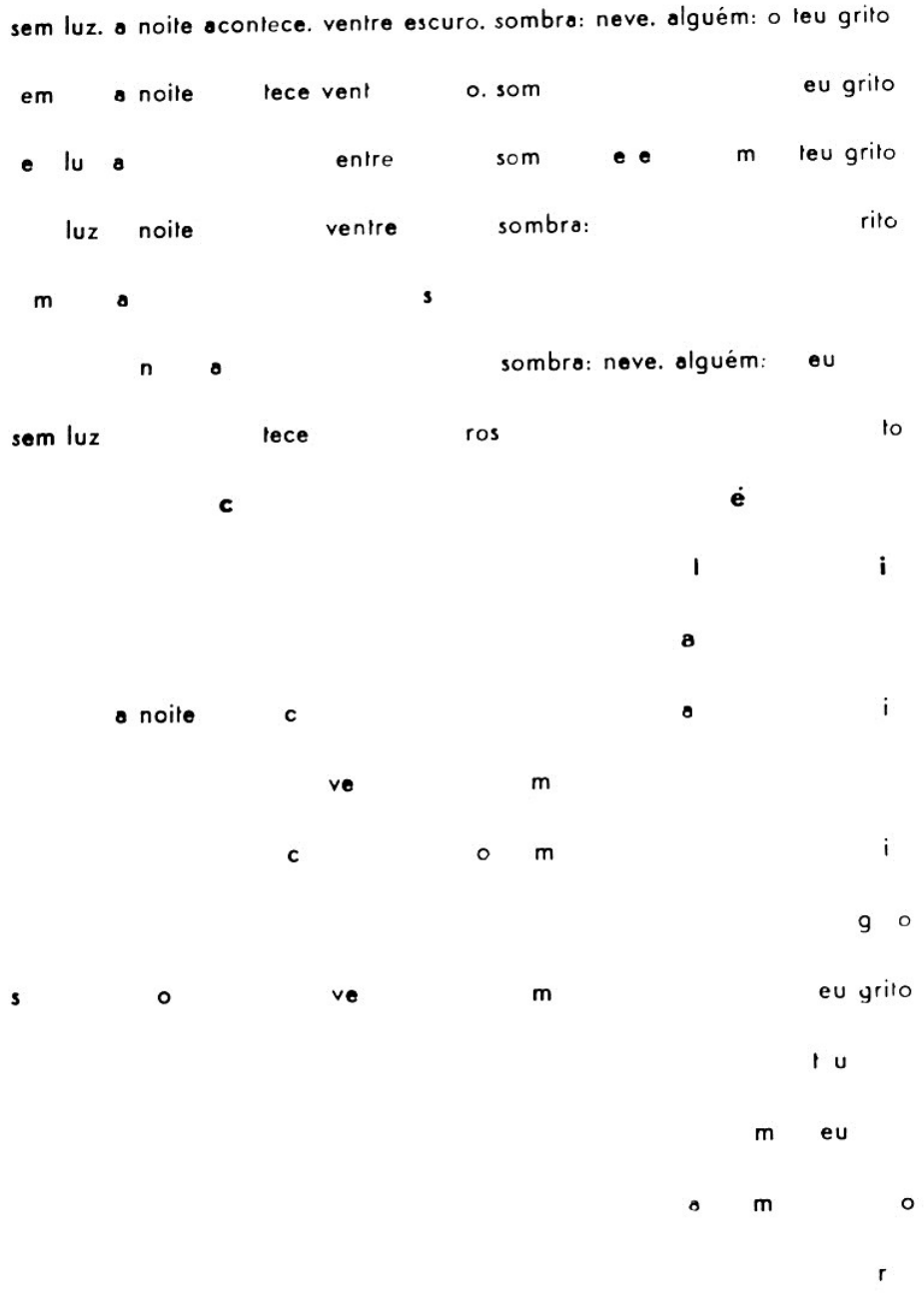


De maneira geral, pode-se afirmar que o poema celebra a antiquíssima lírica do amor. Na versão publicada no caderno da Poex, o poema é dedicado a "Célia", nome que aparece anagramaticamente inscrito no meio do poema. Lembra-nos bem os procedimentos de Augusto de Campos, em seu célebre poetamenos (1953), composto em cores, segundo a "klangfabernmelodie (melodia de timbres)", de Webern (Cf. CAMPOS, A., 2000, p. 65-77), um poema em que as palavras funcionam como se fossem instrumentos de sentenças, sílabas, letras e nas quais os timbres se definem por um tema gráfico-fonético ou ideogramático. Também Augusto inscreve e decompõe o nome de sua musa amada Lygia ao longo dos poemas de amor.

No caso do poema "Homeóstato 1" (Figura 1), de José-Alberto Marques, a primeira linha estabelece um tema, num verso já elíptico, entrecortado, e que vai sendo decomposto de modo que os resíduos de sílabas, fonemas e palavras possibilitam o telegrama amoroso que se inscreve pelos resíduos temporais da cultura: estão lá os elementos líricos, a lua, a noite, o poeta solitário, a amada ausente, o grito solitário do poeta para a noite, quase deserta.

No plano sonoro seria possível identificarmos a melodia distinta daquela que a tradição lírica consagrou, talvez aproximável às escalas da música dodecafônica, como fez Augusto. No plano visual, ao contrário do poeta brasileiro, o poema se mostra mais livre em termos de organicidade. As palavras funcionam como se criassem uma cosmografia própria, preenchendo amplamente a página, executando na mancha movimentos de liberdade ainda que os blocos de escrita estabeleçam conexões múltiplas. Mas assim como o poema de Augusto de Campos, o poema de José-Alberto Marques atualiza as raízes da lírica portuguesa evocando as cantigas dos antigos trovadores. E mais: impõem ao leitor a tarefa de recriar o poema, de ressignificá-lo na leitura da tradição.

Enfim, de maneira um tanto abreviada, estabelecemos aqui conexões entre o poema de Homeóstato e uma das Ex-critas, de José-Alberto Marques, dada essa perspectiva sincrônica, que viemos assinalando: 
Fig. 2 e 3 - Detalhes de Ex-critas, José-Alberto Marques.
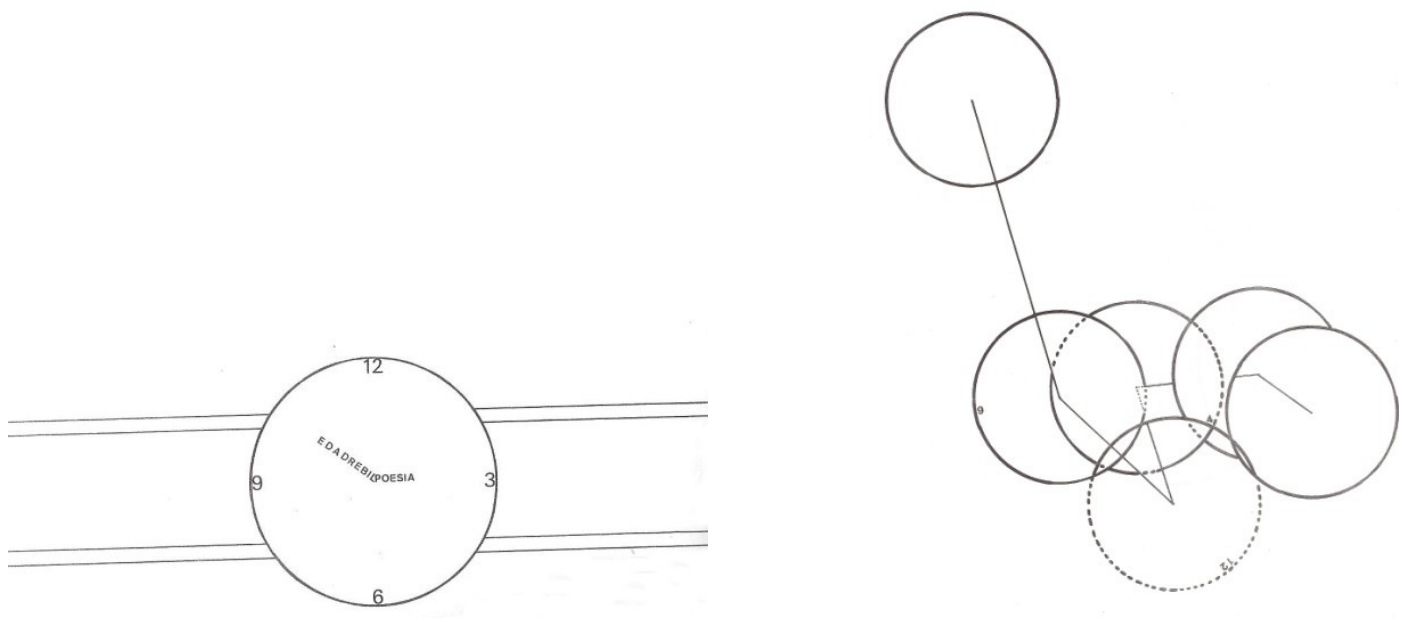

As duas sequências nos induzem pensar o poema transladando de uma dimensão temporal linear para dimensão temporal elíptica, em que o espaço conjuga as múltiplas temporalidades da escrita do poema. A segunda sequência nos leva a pensar num pêndulo "enlouquecido", talvez pelo mal funcionamento, talvez pela mobilidade da extremidade inferior. Mas isso nos permite visualizar na estaticidade da página camadas superpostas ou elípticas de seu movimento. Nesses movimentos, os ponteiros do relógio realizam deslocamentos inesperados, e os próprios relógios estarariam alinhados assincronomamente, como se pode observar pelos números que indicam as horas. As linhas de contornos apresentam hachuras que podem indicar pontos imaginários de encontros, marcas ou margens em que uma leitura poderia reinventar-se.

Nisso, esse poema sem palavras permite-nos reencontrar os de Homeóstatos, em sua capacidade de nos fazer aprofundar o olhar através das superfícies dos textos; encontrar uma razão do poema para além das linguagens codificadas.

É assim que a poesia de José-Alberto Marques (como bem se coloca nesses poemas de Homeóstatos) instiga a leitura, ao se apresentar em sua mobilidade e abertura, levando-nos à ressignificação das tradições poéticas, em consonância com a perspectiva poetográfica assinalada por Alberto Pimenta, e portanto definindo-se por uma consciência crítica do poeta em seu fazer. 


\section{JOSÉ ALBERTO MARQUES: THE POEM AGAINST STATIC IMMUTABILITY}

ABSTRACT: Reading of Homeóstatos, by José-Alberto Marques, to demonstrate how their composition reveals the dynamic process of poetic writing, which gives the poem a sense of a living body. We emphasize that, in this poetic process, the poet reinvents tradition, exposing the poem as an aestheticcritical construction. For this, we read the few critical texts of this poet in contrast to his poetry and fundamental texts to think about experimental poetry, such as E. M. de Melo e Castro, on the poet and the Portuguese experimental poetry; Haroldo de Campos, of synchrony and diachrony; and Alberto Pimenta, about the poetografia, as an autonomous statement element of the poem before the lyrical traditions.

KEYWORDS: Homeóstatos. José-Alberto Marques. Portuguese Experimental Poetry.

\section{Referências}

CAMPOS, Augusto de. Poesia - 1949-1979. São Paulo: Ateliê Editorial, 2000.

CAMPOS, Haroldo. Poética sincrônica; Apostila: Diacronia e sincronia. In: CAMPOS, H. A Arte no horizonte do provável. São Paulo: Perspectiva, 1977. p. 205$212 ; 221-223$.

CASTRO, E. M. de Melo. O homeóstato José-Alberto Marques. In: CASTRO, E. M. de M. Voos da fénix crítica. Lisboa: Edições Cosmos, 1995. p. 183-192.

MARQUES, José-Alberto. British Barthes. Lisboa: Imprensa Nacional-Casa da Moeda, 2011.

. Ex-critas. In: AGUIAR, F.; PESTANA, S. Poemografias: Perspectivas da Poesia Visual Portuguesa. Lisboa: Ulmeiro, 1985. p. 93-96.

. Homeóstatos. In: Arquivo Digital da Po-ex, 1966. Disponível em:

<http://www.po-ex.net/taxonomia/materialidades/planograficas/jose-alberto-marquesoperacao-1-homeostatos>. Acesso em: 30 maio 2015.

. O tempo não tem espaço. In: AGUIAR, F.; PESTANA, S. Poemografias: Perspectivas da Poesia Visual Portuguesa. Lisboa: Ulmeiro, 1985. p. 89-91.

PIMENTA, Alberto. O silêncio dos poetas - precedido de Reflexões sobre a função da arte literária e de A dimensão poética das línguas. Lisboa: Livros Cotovia, 2003.

Recebido em: 19/05/2016.

Aceito em: 15/06/2016. 